\title{
Effective Control of $\mathrm{CH}_{4} / \mathrm{H}_{2}$ Plasma Condition to Synthesize Graphene Nano-walls with Controlled Morphology and Structural Quality
}

\author{
Hyun Jae Park ${ }^{\mathrm{a}}$, Jin-ha Shin ${ }^{\mathrm{a}, \mathrm{b}}$, Kang-il Lee ${ }^{\mathrm{a}}$, Yong Sup Choi ${ }^{\mathrm{a}}$, Young Il Song ${ }^{\mathrm{b}}$, Su Jeong Suh ${ }^{\mathrm{b}}$, and Yong Ho Junga* \\ a Plasma Technology Research Center, National Fusion Research Institute (NFRI), 814-2 Osickdo-dong(SGFEZ), Gunsan-city, \\ Jeollabuk-do, 573-540, South Korea \\ ${ }^{b}$ Advanced Materials Science and Engineering, Advanced Materials and Process Research Center(AMPRC) Sungkyunkwan \\ University, Suwon 440-746, South Korea
}

Received September 21, 2017; revised October 12, 2017; accepted October 30, 2017

\begin{abstract}
The direct growth method is simplified manufacturing process used to avoid damages and contaminants from the graphene transfer process. In this paper, graphene nano-walls (GNWs) were direct synthesized using electron cyclotron resonance (ECR) plasma by varying the $\mathrm{CH}_{4} / \mathrm{H}_{2}$ gas flow rate on the copper foil at low temperature (without substrate heater). Investigations were carried out of the changes in the morphology and characteristic of GNWs due to the relative intensity of hydrocarbon radical and molecule in the ECR plasma. The results of these investigations were then discussed.
\end{abstract}

Keywords: PECVD, Graphene nano-walls, Direct growth, Langmuir probe, Raman, RGA

\section{Introduction}

Graphene, a two-dimensional structure, has attracted considerable attention in an effort to explore its potential applications in various devices, including solar cells, supercapacitors, light-emitting diodes, touch-screen and sensors. The popularity of graphene is due to its excellent electronic property with an electron mobility of $200,000 \mathrm{~cm}^{2} /$ Vs at room temperature, optical property with a transmittance of $97.7 \%$, mechanical property with a Young's modulus of $1 \mathrm{TPa}$, and thermal property with a thermal conductivity of $5000 \mathrm{~W} / \mathrm{mK}$ [1-6].

Graphene synthesizing methods for large area graphene films with high quality have been continuously developed [7-9]. Thermal chemical vapor deposition (CVD) is the most popular technique to overcome the limitations of scalability. However graphene synthesis using CVD techniques cannot change the morphology of the graphene surface because of the limitations intrinsic to the CVD method. On the other hand, the graphene synthesis method using plasma is more easily controlled due to the many process parameters affecting the growing morphology and structure of graphene [10,11]. In this paper, we studied the change of GNWs growth according to the relative ratio of hydrocarbon radical and molecule. we present a direct growth method of GNWs on $\mathrm{Cu}$ (100) foil substrates. The GNWs were directly grown on $\mathrm{Cu}$ foil by methane diluted

*Corresponding author

E-mail: yhjung@nfri.re.kr in hydrogen ECR plasma at low temperature. The density, temperature and potential of plasma were measured using a cylindrical Langmuire probe. We discussed the morphology and characteristic of the GNWs based on the results of fieldemission scattering electron transmission (FE-SEM), residual gas analysis (RGA), Fourier-transform infrared spectroscopy (FT-IR), optical emission spectroscopy (OES) and Raman spectroscopy.

\section{Experimental}

\section{Experimental conditions and sample preparations}

The GNWs were deposited on $\mathrm{Cu}$ foil by ECR plasma system. A schematic illustration of the experimental equipment used in this study in Fig. 1. This system is composed of an electromagnet and a microwave system(without substrate heater). Microwave power is introduced to the plasma chamber through a bending waveguide and a window fabricated of a fused circular quartz. An electromagnet is arranged around the periphery of the circular quartz for ECR plasma excitation. The chamber was pumped to a base pressure of $10^{-6}$ Torr before synthesis and the input microwave power of $1.5 \mathrm{~kW}$ and process pressure of a few mTorr were introduced while GNWs synthesized. $\mathrm{Cu}$ foil with a thickness of $25 \mathrm{um}$ and area of $100 \mathrm{~cm}^{2}$ was used as the experimental substrate (99.95\%, Alfa Aesar). Table 1 shows the experimental conditions of the GNWs depositions with the gas flow rate and interaction times. The first step involved plasma cleaning and annealing of the substrate surface, while the 


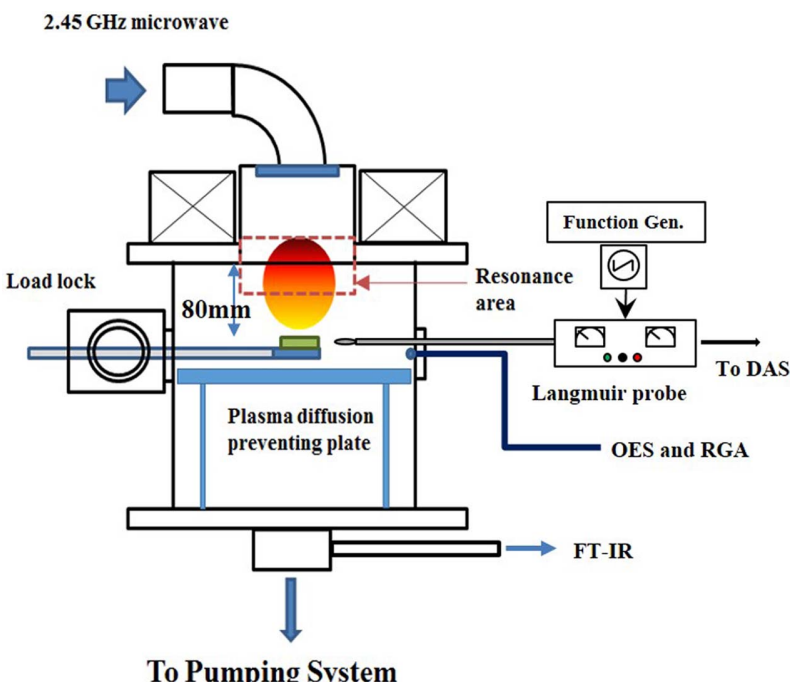

Figure 1. Schematic illustration of the experimental ECR plasma system.

Table 1. Conditions of GNWs for the gas flow rate on $\mathrm{Cu}$ foil.

\begin{tabular}{ccccc}
\hline \hline \multirow{2}{*}{$\begin{array}{c}\text { Sample } \\
\text { name }\end{array}$} & \multicolumn{2}{c}{$\begin{array}{c}\text { Flow rate } \\
{[\mathrm{sccm}]}\end{array}$} & $\begin{array}{c}\text { Step 1: } \mathrm{H}_{2} \\
\text { plasma }\end{array}$ & $\begin{array}{c}\text { Step2: } \mathrm{H}_{2}+\mathrm{CH}_{4} \\
\text { plasma }\end{array}$ \\
\cline { 2 - 5 } & $\mathrm{H}_{2}$ & $\mathrm{CH}_{4}$ & Interaction time [min] \\
\hline GNWs_20 & 200 & 20 & 3 & 5 \\
GNWs_40 & 200 & 40 & 3 & 5 \\
GNWs_120 & 200 & 120 & 3 & 5 \\
GNWs_180 & 200 & 180 & 3 & 5 \\
\hline
\end{tabular}

second step involved the deposition of the GNWs on the substrate. $\mathrm{H}_{2}$ gas was used in the plasma cleaning and annealing of the $\mathrm{Cu}$ substrate. The second step of the GNWs deposition process was performed using the mixed gas plasma of $\mathrm{CH}_{4}$ (carbon precursor gas) and $\mathrm{H}_{2}$. The input microwave power to generate the plasma was $1.5 \mathrm{~kW}$. The ECR discharge point was set at approximately $150 \mathrm{~mm}$ from the $\mathrm{Cu}$ substrate.

\section{Measurements and analysis}

FE-SEM (Gemini, Zeiss) was carried out to observe the surface morphology of the GNWs. The crystallinity and structural information of the synthesized GNWs were obtained by micro-Raman spectroscopy (in-Via Raman microscope, Renishaw) using a $532 \mathrm{~nm}$ laser. A minimal laser power of $\sim 1 \mathrm{~mW}$ was used during the measurements to avoid damage of the GNWs. The optical emission spectroscopy (focla length : $750 \mathrm{~mm}$, detector : CCD iDus 420 , Andor) allows observations of only radicals where optical emission transitions are permitted by selection rules. On the other hand, optical emission transitions can be forbidden in many other radicals such as $\mathrm{CH}_{3}, \mathrm{CH}_{2}$, $\mathrm{C}_{2} \mathrm{H}_{2}$, etc. Therefore, other diagnostics such as FT-IR, RGA, ultraviolet absorption spectroscopy, etc. should be carried out to detect species that could also play an important role in the growth of GNWs [12]. An RGA (RGA100, Stanford Research System) is attached to the side wall of the chamber to investigate the density of the synthesis radicals and molecules. FT-IR (Vertex 70, Bruker) spectrum was measured for hydrocarbon molecule intensity in the range of $500-4000 \mathrm{~cm}^{-1}$. The density, temperature and potential of plasma were measured using the cylindrical Langmuire probe (handmade).

\section{Results and Discussion}

\section{Synthesis and crystallinity properties of GNWs}

The morphologies of the synthesized GNWS are shown in Fig. 2 at each conditions. When increasing the inlet $\mathrm{CH}_{4}$ flow rate, the inter layer spacing and size of GNWs are further increased. The results show that the $\mathrm{CH}_{4} / \mathrm{H}_{2}$ ratio is an important factor in the synthesis of GNWs. Raman spectroscopy is an effective tool to evaluate nano-carbon materials. Fig. 3 shows the Raman spectrum of the GNWs on $\mathrm{Cu}$ foil by ECR plasma. Three peaks were observed at 1350,1580 , and $2700 \mathrm{~cm}^{-1}$, corresponding to the $\mathrm{D}$ band, $\mathrm{G}$ band, and 2D band, respectively. The $\mathrm{D}$ band and the 2D band, generated by double resonant Raman scattering, can ofen be used to evaluate the grain size of graphene and the number of graphene layers. And intensity ratio of the $\mathrm{D}$ and $G$ peaks, $I_{D} / I_{G}$ indicates that size of crystalline grains as well as the inter defect distance $[13,14]$. The $\mathrm{I}_{\mathrm{D}} / \mathrm{I}_{\mathrm{G}}$ ratio tend to increase as the inlet $\mathrm{CH}_{4}$ flow rate increases. This result indicates the degradation of the quality of the GNWs. However, the $I_{2 D} / I_{G}$ ratio decreased as the inlet $\mathrm{CH}_{4}$ flow rate increased. This implies an increase in the
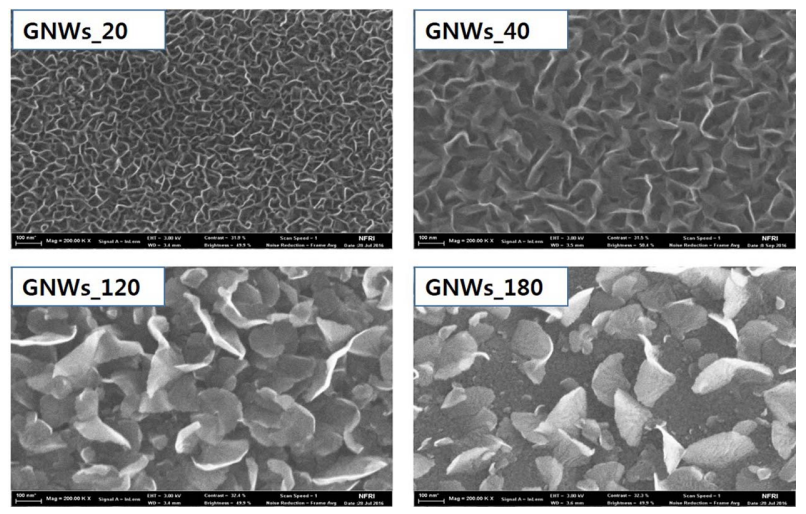

Figure 2. Plan view FE-SEM images of GNWs grown on $\mathrm{Cu}$ foil at 2-4 mTorr pressure with ECR plasma power of $1.5 \mathrm{~kW}$. Scale bars, $100 \mathrm{~nm}$.
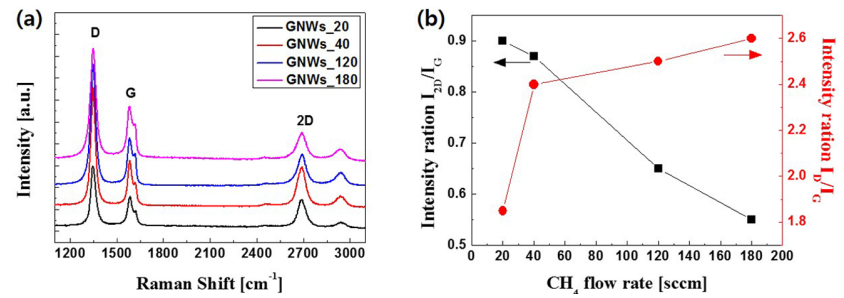

Figure 3. Comparison of Raman spectra at $514 \mathrm{~nm}$ for GNWs at each condition. (a) the intensities of the spectra are vertically offset for clarity (b) intensity ratio of $D, 2 D$ and $G$ band. 
graphene nano wall layer of the GNWs [15].

\section{OES and RGA results during to synthesis GNWs}

Fig. 4 show the OES results from the $\mathrm{CH}_{4} / \mathrm{H}_{2}$ plasma at each conditions. Optical emission lines derived from the $\mathrm{CH}\left(\mathrm{B}^{2} \Sigma-\mathrm{X}^{2} \Pi\right.$ and $\left.\mathrm{A}^{2} \Delta-\mathrm{X}^{2} \Pi\right), \mathrm{H}_{\gamma}(434 \mathrm{~nm})$ and $\mathrm{C}_{2}$ swan system (approximately $516.5 \mathrm{~nm}$ ) were principally observed. The detection of $\mathrm{CH}$, the $\mathrm{C}_{2}$ species, and the atomic and molecular hydrogen imply an effective dissociation of the C source molecules by the ECR plasma. Fig. 4(b) shows the increase in the $\mathrm{CH}$ radical emission intensity as the inlet $\mathrm{CH}_{4}$ flow rate increases. We calculated the $\mathrm{CH}$ radical rotational temperature using the results shown in Fig. 4(b) and identified the correlation between the calculation and synthesis of the GNWs [16]. However, it is difficult to calculate the current measurement system because of its low resolution. Therefore, we performed additional experiments
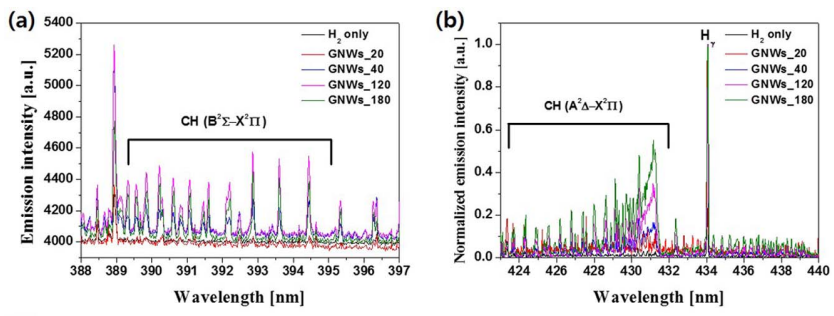

(c)

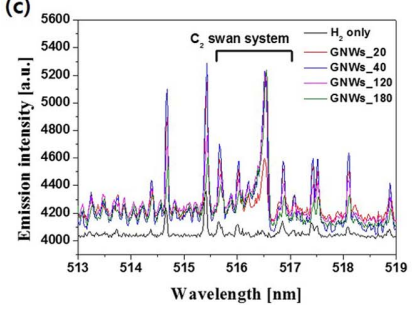

Figure 4. Typical optical emission spectra from $\mathrm{CH}_{4} / \mathrm{H}_{2}$ plasma at each condition. (a) $\mathrm{CH}\left(\mathrm{B}^{2} \Sigma-\mathrm{X}^{2} \Pi\right)$ system, (b) measured $\mathrm{CH}$ $\left(\mathrm{A}^{2} \Delta-\mathrm{X}^{2} \Pi\right)$ system and $\mathrm{H} \gamma$ emission intensity normalized by $\mathrm{H} \gamma$ peak intensity (at $434 \mathrm{~nm}$ ), and (c) $C_{2}$ swan system emission results.
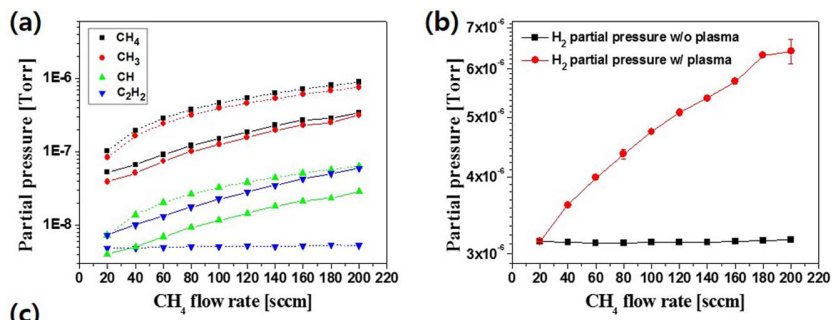

(c)

$$
\mathrm{CH}_{4} \text { flow rate [sccm] }
$$

$\mathrm{CH}_{4}$ flow rate $[\mathrm{sccm}]$

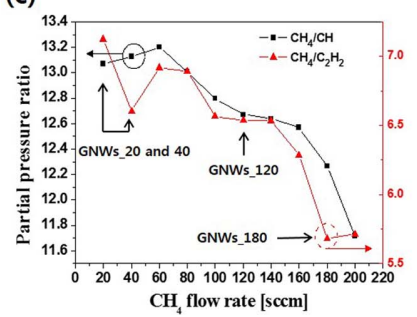

Figure 5. Partial pressure(or partial pressure ratio) variations of (a) hydrocarbon radical and molecule, (b) $\mathrm{H}_{2}$, and (c) $\mathrm{CH}_{4} /$ $\mathrm{CH}$ and $\mathrm{CH}_{4} / \mathrm{C}_{2} \mathrm{H}_{2}$ as functions of $\mathrm{CH}_{4}$ flow rate measured by RGA. after the equipment improvement. As explained above, the optical emission transitions might be forbidden in many other radicals such as $\mathrm{CH}_{3}, \mathrm{CH}_{2}, \mathrm{C}_{2} \mathrm{H}_{2}$, etc. Therefore, hydrocarbon radicals and molecules were measured using RGA.

$\mathrm{CH}_{4}$ provides hydrogen species during its dissociation process into active species. In thermal CVD, only $\sim 0.0002 \%$ of incoming methane dissociates from the active species in the gas phase at a temperature of $900^{\circ} \mathrm{C}$. However, more than $80 \%$ of methane dissociates from other species such as $\mathrm{H}, \mathrm{H}_{2}, \mathrm{CH}, \mathrm{C}_{2} \mathrm{H}_{2}$, etc. due to the advantage of plasma [17]. The measured RGA results are shown in Fig. 5. Fig. 5(a) shows the partial pressure of hydrocarbon molecules and radicals. The solid line represents the measured results of the ECR plasma generation and the dotted line represents the measured results of the pre-plasma generation. The partial pressure of $\mathrm{CH}_{4}, \mathrm{CH}_{3}$ and $\mathrm{CH}$ was relatively reduced compared to the pre-plasma generation, while the partial pressure of $\mathrm{C}_{2} \mathrm{H}_{2}$ increased during plasma generation. Fig. 5(b) shows the variation of partial pressure of $\mathrm{H}_{2}$ as a function of the $\mathrm{CH}_{4}$ flow rate. The hydrogen partial pressure was increased with increasing $\mathrm{CH}_{4}$ methane flow rate during the plasma generation. The increase of the inter layer spacing of the GNWs shown in Fig. 2 is due to an increase in the hydrogen partial pressure. This is because hydrogen, hydrogen atoms, and radicals attack the carbon atoms at surface defects via $\mathrm{C}-\mathrm{H}$ covalent bond formation and $\mathrm{C}-\mathrm{C}$ bon breakage [18]. Fig. 5(c) shows the partial pressure ratio of $\mathrm{CH}_{4} / \mathrm{CH}$ and $\mathrm{CH}_{4} / \mathrm{C}_{2} \mathrm{H}_{2}$, and the experiments condition GNWs_20, GNWs_40, GNWs_120, and GNWs_180. When the $\mathrm{CH}_{4}$ flow rate was increasing, the partial pressure of $\mathrm{CH}$ and $\mathrm{C}_{2} \mathrm{H}_{2}$ increased compared to $\mathrm{CH}_{4}$. The growth of the GNWs requires more atomic carbon from the process of the hydrocarbon radicals and molecules via $\mathrm{H}$-bond breaking and $\mathrm{H}_{2}$ molecule formation, respectively. $\mathrm{C}_{2} \mathrm{H}_{2}$ had a higher dehydrogenation energy $(879 \mathrm{~kJ} / \mathrm{mole})$ than other hydrocarbon molecules and radicals. In the case of $\mathrm{C}_{2} \mathrm{H}_{2}$, difficulties arose in making atomic carbon because of the carbon triple bond.

\section{Langmuir probe analysis and FT-IR measured results during to synthesis GNWs}

Fig. 6 shows the FT-IR absorption spectra of the exhaust gas during the process of the synthesis the GNWs. $\mathrm{CH}_{4}$ was identified from the peak in the wave number range of $1220-1380 ; 2850-3150 \mathrm{~cm}-1$. It should be noted that the diatomic molecules such as $\mathrm{H}_{2}$ could not be identified by FT-IR. As the flow rate of $\mathrm{CH}_{4}$ increased, the increase of $\mathrm{C}_{2} \mathrm{H}_{2}$ and Alkyne intensity was observed. In the case of $\mathrm{C}_{2} \mathrm{H}_{2}$ and Alkyne, these compounds are of carbon triple bonds and have a high binding energy, so it is difficult to generate carbon atoms by breaking bonds. Therefore, the increase of the applied $\mathrm{CH}_{4}$ flow rate increased the ratio of the carbon triple bond, it is thus difficult to growth GNWs 

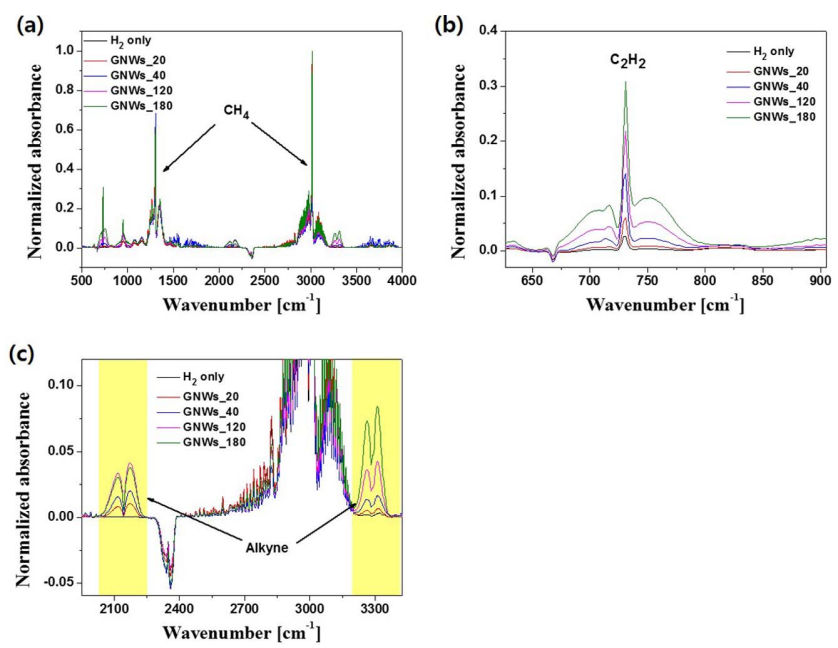

Figure 6. (a) Measured FT-IR absorption spectra normalized by $\mathrm{CH}_{4}$ main peak intensity (approximately $3018 / \mathrm{cm}$ ) variations as function of $\mathrm{CH}_{4}$ flow rate (b) $\mathrm{C}_{2} \mathrm{H}_{2}$ and (c) alkyne identified by the peak in the wave number range of $650-800 / \mathrm{cm}$ and 2050-2200;3200-3400/cm, respectively.

(a)

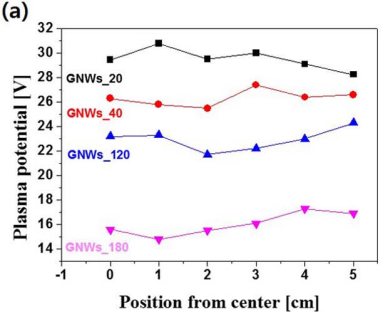

(b)

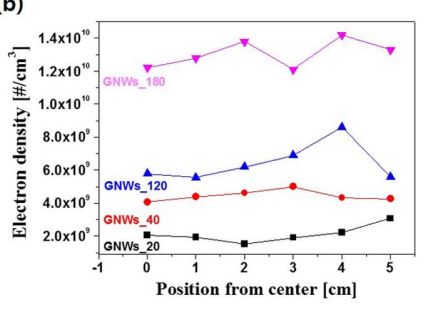

(c)

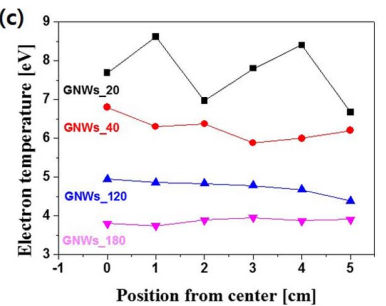

Figure 7. (a) Plasma potential, (b) electron density, and (c) electron temperature of the ECR plasma equipment at each condition.

due to the difficulty in producing carbon atoms as a source of the synthesis of GNWs. The increasing $\mathrm{C}_{2} \mathrm{H}_{2}$ intensity is due to the inelastic collisions of methane molecules with free electrons (generated by ECR plasma), leading to the formation of some active radicals such as $\mathrm{CH}_{3}, \mathrm{CH}_{2}, \mathrm{CH}$ and $\mathrm{C}_{2} \mathrm{H}$. The formation of gaseous $\mathrm{C}_{2} \mathrm{H}_{2}$ can be attributed to the following two possible channels [19]:

1) Recombination of radicals: $\mathrm{CH}+\mathrm{CH} \rightarrow \mathrm{C}_{2} \mathrm{H}_{2} ; \mathrm{H}+$ $\mathrm{C}_{2} \mathrm{H} \rightarrow \mathrm{C}_{2} \mathrm{H}_{2}$, etc.

2) Inelastic collisions of methane molecules with radicals: $\mathrm{C}+\mathrm{CH}_{4} \rightarrow \mathrm{C}_{2} \mathrm{H}_{2}+{ }_{2} \mathrm{H}$, etc.

Ethane $\mathrm{C}_{2} \mathrm{H}_{6}$ has been widely reported as an important gaseous hydrocarbons in dielectric-barrier discharge (DBD) and pulsed glow plasma because of the recombination of high concentration $\mathrm{CH}_{3}$ radicals [20,21]. However, no obvious $\mathrm{C}_{2} \mathrm{H}_{6}$ was detected in the current work. This is possibly because the electron temperature from the ECR plasma is a greater than that of the DBD and glow plasma. Therefore, an enhanced dehydrogenation process of $\mathrm{C}_{2} \mathrm{H}_{6}$ is induced by the impact of electrons or radical collisions. Plasma physicists use Langmuir probes in low temperature plasmas to measure the electron density, electron temperature and plasma potential. A Langmuir probe was located $10 \mathrm{~mm}$ above the substrate and was used to measure the parameters in the radial direction at $10 \mathrm{~mm}$ intervals. The Laframboise plot is used to determine the plasma parameters [22]. The measured plasma temperature, density and potential are shown in Fig. 7.

The measured plasma potential of each experimental conditions is shown in Fig. 7(a). It can be confirmed that the plasma potential decreased as the applied $\mathrm{CH}_{4}$ gas flow rate increases. The intensity of the plasma potential is proportional to the intensity of the electric field formed perpendicularly to the $\mathrm{Cu}$ foil surface. Therefore, it can be confirmed, as shown in Fig. 2, that the intensity of the electric field on the surface of the $\mathrm{Cu}$ foil decreased and the GNWs are not synthesized vertically with the increase of the applied methane gas flow rate increase [23]. The bulk of the plasma is ion and electron densities are nearly equal, $\mathrm{n}_{\mathrm{i}} \approx \mathrm{n}_{\mathrm{e}}$, a condition commonly known as "quasi-neutral". Fig. 7(b) shows that the electron density increased as the $\mathrm{CH}_{4}$ gas flow rate was increased because the pressure inside the chamber increases. On the other hand, Fig. 7(c) shows the reduction of electron temperature due to the reduced mean free path of electrons. $1 \mathrm{eV}$ is approximately $11600 \mathrm{~K}$. The reduction of the electron temperature affects the surface temperature change of the $\mathrm{Cu}$ foil as well as the growth of GNWs. $\mathrm{CH}_{4}$ undergoes a dehydrogenation process to produce four $\mathrm{H}$ atoms and $\mathrm{a} \mathrm{C}$ atom needed for the growth of the GNWs. The relative dehydrogenation energy of the $\mathrm{CH}_{4}$ on the $\mathrm{Cu}$ surface increases as the dehydrogenation process progresses [24]. Therefore, if the electron temperature is low, the supply of carbon necessary for the growth of GNWs cannot proceed smoothly.

\section{Conclusions}

We have investigated the properties of GNWs synthesized using ECR plasma and the ECR plasmas' characteristics was diagnosed. As the flow rate of $\mathrm{CH}_{4}$ is increased, the partial pressure of hydrogen increases, which etches the carbon onto the surface of the GNWs, destroying the $\mathrm{C}-\mathrm{C}$ bond and increasing the $\mathrm{C}-\mathrm{H}$ covalent bond, and increase the number of carbon triple bond molecules. This is considered an unfavorable environment for GNWs growth. However, the increase of the relative partial pressure of the $\mathrm{CH}$ radical due to the increase of the applied $\mathrm{CH}_{4}$ flow rate is considered to be the cause of the carbon supply for the GNWs growth because the binding energy of the $\mathrm{CH}$ radical is as low as $3.72 \mathrm{eV}$. Therefore, the appropriate hydrocarbon radical and molecular ratios, 
and the hydrogen partial pressure are considered necessary. The electron temperature and plasma potential decreased with the increasing $\mathrm{CH}_{4}$ flow rate. The changes in the electron temperature and plasma potential affect to changes in the temperature and electric field on the surface of the $\mathrm{Cu}$ foil, influencing GNWs growth. Plasma diagnostics should thus be performed in GNWs synthesis research in which plasma is used.

\section{Acknowledgments}

This work was supported by R\&D Program of 'Plasma Convergence \& Fundamental Research' through the National Fusion Research Institute of Korea (NFRI) funded by the Government funds and the Degree \& Research Center Program of the Korea Research Council of Fundamental Science and Technology.

This study was supported by a grant from the Regional Innovation Center (RIC, B0008787) at Sungkyunkwan University and the MSIP (Ministry of Science, ICT and Future Planning), Korea, under the ITRC (Information Technology Research Center) support program (IITP2016-H8501-16-1009) supervised by the IITP (Institute for Information and communications Technology Promotion).

\section{References}

[1] H. Wang, Y. Yang, Y. Liang, J. T. Robinson, Y. Li, A. Jackson, Y. Cui, and H. Dai, NanoLett. 11, 2644-2647 (2011).

[2] Y. Zhu, S. Murali, Meryl D. Stoller, K. J. Ganesh, W. Cai, P. J. Ferreira, A. Pirkle, R. M. Wallace, K. A. Cychosz, M. Thommes, D. Su, E. A. Stach, and R. S. Ruoff, Science 332, 1537-1541 (2011).

[3] T. H. Han, Y. Lee, M. Choi, S. H. Woo, S. H. Bae, B. H. Hong, J. H. Ahn, and T. W. Lee, Nat. Photonics 6, 105-110 (2012).
[4] M. Layani, A. Kamyshny, and S. Magdassi, Nanoscale. 6, 55815591 (2014).

[5] S. Liu, L. Zhou, L. Yao, L. Chai, L. Li, G. Zhang, Kankan, and K. Shi, J. Alloys Compd. 612, 126 (2014).

[6] S. M. Kim and K. K. Kim, Appl.Sci.Converg.Technol. 24(6), 268 (2015).

[7] S. Bae, H. Kim, Y. Lee, X. Xu, J. S. Park, Y. Zheng, J. Balakrishnan, T. Lei, H. R. Kim, K. S. Kim, B. Ozyilmaz, J. H. Ahn, B. H. Hong, and S. Iijima, Nature Nanotechnology 5, 574 (2010).

[8] K. S. Kim, Y. Zhao, H. Jand, S. Y. Lee, J. M. Kim, K. S. Kim, J. H. Ahn, P. Kim, J. Y. Choi, and B.H. Hong, Nature 457, 706 (2009).

[9] X. Li, W. Cai, J. An, S. Kim, J. Nah, D. Yang, R. Piner, A. Velamakanni, I. Jung, E. Tutuc, S. K. Banerjee, L. Colombo, and R. S. Ruoff, Science 324, 1312 (2009).

[10] U. Cvelbar, B. Markoli, I. Poberaj, A. Zalar, L. Kosec, and S. Spaic, Appl. Surf. Sci. 253, 1861 (2006).

[11] D. Mariotti and R Mohan Sankaran, J. Phys. D: Appl. Phys. 44, 174023 (2011).

[12] H. J. Cho, H. Kondo, K. Ishikawa, M. Sekine, M. Hiramatsu, and M. Hori, Carbon 68, 308 (2014).

[13] L. M. Malard, M.A. Pimenta, G. Dresselhaus, and M. S. Dresselhaus, Phys Rep 473, 51 (2009).

[14] N. Soi, S. S. Roy, C. O'Kane, J. A. D. McLaughlin, T. H. Lim, and C.J. D. Hetherington, CrystEngComm 13, 312 (2011).

[15] Z. Ni, Y. Wang, T. Yu, and Z. Shen, Nano Res. 1, 237 (2008).

[16] J. S. Kim and M. A. Cappelli, J. Appl. Phys. 84, 4595 (1998).

[17] D. B. Hash and M. Meyyappan, J. Appl. Phys. 93, 750 (2002).

[18] R. Yang, L. Zhang, Y. Wang, Z. Shi, D. Shi, H. Gao, E. Wang, and G. Zhang, Adv. Mater. 22, 4014 (2010).

[19] Z. Bo, J. Yan, Z. Li, Y. Chi, and K. Cen, I. J. Hydrogen energy 33, 5545 (2008).

[20] Y. Li, C. J. Liu, B. Eliasson, and Y. Wang, Energy \& Fuels 16, 864 (2002).

[21] N. Derkaoui, C. Rond, K. Hassouni, and A. Gicquel, J. Appl. Phys. 115, 233301 (2014).

[22] G. Narasimhan and Ch. Steinbruchel, J. Vac. Sci. Technol. A 19, 376 (2001).

[23] M. Zho, J. Wang, Brian C. Holloway, R. R. Outlaw, X. Zhao, K. Hou, V. Shutthanandan, and D. M. Manos, Carbon 45, 2229 (2007).

[24] W. Zhang, P. Wu, Z. Li, and J. Yang, J. Phys. Chem. C 115, 17782 (2011). 